\title{
Laboreal
}

Volume $12 \mathrm{~N}^{\circ} 2$ | 2016

Equipamentos de Proteção Individual II

\section{O desconforto térmico provocado pelos equipamentos de proteção individual (EPI) utilizados na aplicação de agrotóxicos}

El disconfort térmico causado por el uso de equipos de protección personal (EPP) durante el proceso de pulverización de plaguicidas

L'inconfort thermique cause par l'utilisation d'equipements de protection individuelle (EPI) pendant le processus de pulverisation de pesticides The thermal discomfort caused by personal protective equipment (PPE) used while spraying pesticides

Marcelo Motta Veiga, Ronaldo Almeida e Francisco Duarte

\section{OpenEdition}

\section{Journals}

Edição electrónica

URL: http://journals.openedition.org/laboreal/2540

DOI: $10.4000 /$ laboreal. 2540

ISSN: 1646-5237

Editora

Universidade do Porto

Refêrencia eletrónica

Marcelo Motta Veiga, Ronaldo Almeida e Francisco Duarte, « O desconforto térmico provocado pelos equipamentos de proteção individual (EPI) utilizados na aplicação de agrotóxicos », Laboreal [Online], Volume $12 \mathrm{~N}^{0} 2$ | 2016, posto online no dia 01 dezembro 2016, consultado o 08 outubro 2019. URL : http://journals.openedition.org/laboreal/2540; DOI : 10.4000/laboreal.2540

Este documento foi criado de forma automática no dia 8 outubro 2019

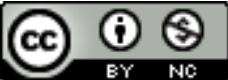

Laboreal está licenciado com uma Licença Creative Commons - Atribuição-NãoComercial 4.0 Internacional. 


\section{O desconforto térmico provocado pelos equipamentos de proteção individual (EPI) utilizados na aplicação de agrotóxicos}

El disconfort térmico causado por el uso de equipos de protección personal (EPP) durante el proceso de pulverización de plaguicidas

L'inconfort thermique cause par l'utilisation d'equipements de protection individuelle (EPI) pendant le processus de pulverisation de pesticides The thermal discomfort caused by personal protective equipment (PPE) used while spraying pesticides

Marcelo Motta Veiga, Ronaldo Almeida e Francisco Duarte

\section{NOTA DO EDITOR}

http://dx.doi.org/10.15667/laborealxii0216mmv

Manuscrito recebido em : março/2016

Aceite após peritagem : maio/2016

\section{1 - Introdução}

1 Um grande número de pessoas se expõe ao calor durante o processo de trabalho. 0 estado de conforto térmico é individual e depende de uma combinação de fatores intrínsecos e extrínsecos. As reações fisiológicas às atividades realizadas determinam a sensação de conforto ou de desconforto térmico. Portanto, há variabilidades interindividuais nessa avaliação, uma sensação térmica confortável para uma pessoa, pode ser desconfortável para outra. 
2 A fisiologia térmica do corpo humano é complexa, funcionando como um sistema termodinâmico que se termorregula para manter a temperatura interna corporal próxima de $37^{\circ} \mathrm{C}$. Este balanço térmico se dá numa relação entre o calor produzido pelo corpo (taxa de metabolismo no trabalho realizado), o calor cedido ao ambiente pela pele (calor latente e calor sensível) e pela respiração. Essa capacidade de manter a temperatura corporal relativamente constante independente das condições ambientais é vital para saúde humana. Por essa capacidade de regular a produção, a absorção e a perda de calor, os seres humanos são homeotermos (Lim, Byrne \& Lee, 2008).

3 No entanto, pequenas oscilações na temperatura corporal fora da faixa ótima (36,5ำ$37,0^{\circ} \mathrm{C}$ ) afetam a condição física e mental, podendo levar a comprometimentos fisiológicos e patológicos. $\mathrm{O}$ desconforto térmico ocorre quando esses mecanismos de regulação natural da temperatura corporal falham. Algumas combinações de esforço físico e de exposição ao calor podem levar esse desconforto ao estresse térmico dos trabalhadores.

4 O desempenho humano em qualquer atividade laboral é prejudicado pelo desconforto térmico. Alguns estudos sobre o conforto térmico no ambiente laboral analisaram os efeitos fisiológicos da exposição a diferentes temperaturas e as ações necessárias para reduzir seus efeitos nocivos à saúde humana (Correia, 2005; Havenith, 1999; Veiga, Duarte, Meirelles, Garrigou \& Baldi, 2007 ; Almeida, Veiga, Duarte, Meirelles \& Veiga, 2012 ; Ruas, 2002).

O processo de trabalho rural apresenta risco potencial ao estresse térmico. A jornada de um trabalhador rural pode superar 12 horas diárias em condições ambientais desfavoráveis, principalmente nas variáveis temperatura e umidade. Na aplicação de agrotóxicos, os trabalhadores rurais necessitam utilizar equipamentos de proteção individual (EPIs). A simples utilização de uma vestimenta impermeável sobre o corpo influencia na forma como se dá a termorregulação corporal. 0 equilíbrio térmico natural é alterado pela dificuldade da perda de calor por convecção, radiação e evaporação, resultando em um aumento na temperatura corporal. O tamanho da interferência no processo de termorregulação corporal devido ao uso de EPI nas atividades rurais está diretamente relacionado ao design do EPI utilizado. As características de projeto dos EPI devem ser definidas de forma a oferecer a proteção necessária ao trabalhador e ao mesmo tempo controlar os possíveis efeitos negativos relativos à elevação da temperatura corporal.

6 Este estudo analisou o efeito negativo na termorregulação corporal e na sensação térmica dos trabalhadores rurais provocado pela utilização de Equipamentos de Proteção Individual (EPIs) para proteção contra a contaminação de agrotóxicos.

\section{2 - Conforto térmico e os EPI utilizados na agricultura}

7 O corpo humano pode ser considerado um sistema termodinâmico em estado de equilíbrio (Prek, 2004). A dissipação do calor corporal por convecção, pela evaporação do suor e pela condução entre os tecidos são as principais respostas térmicas do corpo humano ao ambiente externo (Farrington, Rugh, Bharathan \& Burke, 2004). Qualquer elemento que aumente ou diminua essa capacidade de perda de calor afeta o processo natural de termorregulação e pode ser prejudicial à saúde. A saúde corporal depende da manutenção da temperatura corporal próxima dos $37^{\circ} \mathrm{C}$ (Moran \& Mendal, 2002). 
Desvios superiores $a \pm 3,5^{\circ} \mathrm{C}$ na temperatura corporal podem resultar em prejuízo fisiológico e fatalidade (Lim et. al., 2008).

8 A produção de calor é um dos principais resultados do metabolismo durante o esforço físico nas atividades laborais e poderia elevar a temperatura corporal a níveis perigosos em poucos minutos caso não houvesse esse sistema eficiente de equilíbrio da temperatura (McArdle, Katch \& Katch 2003).

9 Alguns fatores climáticos (temperatura ambiente, umidade e velocidade do vento) podem ser medidos com facilidade e não variam muito em pequenos espaços de tempo. No entanto, variáveis fisiológicas, como a temperatura corporal durante o processo trabalho e a sensação térmica do trabalhador não são tão simples de serem obtidas. Em casos como os trabalhadores rurais, além dos sintomas agudos à exposição a altas temperaturas, adicionam-se os efeitos cumulativos da carga térmica. A carga térmica é o somatório das fontes de geração de calor a que uma pessoa é submetida durante uma jornada de trabalho. No caso dos trabalhadores rurais, praticamente todo o processo de trabalho é realizado sob os efeitos diretos da temperatura.

Os limites legais estabelecidos para conforto térmico e para temperaturas extremas estão baseados nas reações agudas de trabalhadores expostos ao calor e não nos seus efeitos crônicos. Por isso, pode-se dizer que a literatura sobre a exposição contínua e prolongada de trabalhadores ao calor ainda carece de futuros estudos (Wood, 2004).

11 O EPI é considerado uma tecnologia complementar de proteção do trabalhador rural que utiliza agrotóxicos. O uso de EPIs deveria assegurar a proteção do trabalhador, evitando que o mesmo entre em contato com agentes prejudiciais a saúde.

Um EPI inadequado pode provocar um estado de desconforto térmico do trabalhador. Esta situação ocorre devido à necessidade da utilização de EPI agravado pelo esforço do trabalhador para a realização da tarefa que pode durar várias horas e muitos dias consecutivos.

13 Vários autores já pesquisaram os aspectos fisiológicos e sua relação com atividade, vestimenta e termorregulação. Estes estudos demonstraram que há uma interferência da vestimenta no processo de termorregulação. Vestimentas mais fechadas inibem a dissipação de calor elevando a temperatura corporal de forma mais rápida. Uma pessoa utilizando vestimentas leves e executando uma atividade física de baixa intensidade elevaria sua temperatura em $0,5^{\circ} \mathrm{C}$ após 30 minutos. A mesma pessoa utilizando uma vestimenta mais fechada, executando a mesma tarefa elevaria $0,7^{\circ} \mathrm{C}$ sua temperatura corporal, no mesmo espaço de tempo (Gavin, 2003). McArdle et al. (2003) exemplificaram que uma pessoa executando uma atividade moderada utilizando roupas leves levaria em média 90 minutos para elevar $1,5^{\circ} \mathrm{C}$ sua temperatura corporal ; caso utilize uma roupa impermeável e sintética esse tempo cairia para 20 minutos. Uma roupa comum diminui a velocidade de perda de calor em aproximadamente metade daquela de um corpo desnudo (Guyton \& Hall, 2006).

14 Grande parte dos EPIs rurais é feito de material impermeável ou impermeabilizado, pela necessidade básica de tentar evitar a contaminação do trabalhador com o agrotóxico a um custo relativamente baixo. Com isso, pode-se inferir que o tipo de EPI e as condições ambientais interferem no conforto térmico do trabalhador durante o processo de trabalho (Havenith, 1999).

15 A partir dessas informações, pode-se inferir que uma vestimenta (EPI) que foi projetada para isolar o trabalhador do ambiente de forma a evitar a sua contaminação por 
agrotóxicos, altera de forma significativa a capacidade de troca do calor corporal com o ambiente, afetando os mecanismos fisiológicos de termorregulação.

No caso de lavouras em ambientes de forte calor e de elevada umidade, a utilização de EPI pode provocar o estresse térmico, devido aos seguintes fatores : a evaporação do suor é limitada pela alta umidade e pelo isolamento da vestimenta ; a produção de calor corporal em função do esforço físico contribui para o acúmulo de energia térmica no indivíduo, que não é dissipada devido ao uso do EPI ; o acúmulo de energia térmica provoca aumento da sudorese que pode levar ao estado de desidratação ; e a frequência cardíaca também se eleva, significando uma sobrecarga do organismo.

Portanto, a utilização do EPI dificulta a perda de calor para o ambiente, tendo em vista que o calor sensível da pele deve passar pela vestimenta até chegar ao ambiente, ou seja, o processo ocorre em duas etapas: Da superfície da pele até a superfície da vestimenta (convecção) e da superfície da vestimenta para o ambiente (condução).

Da mesma forma, a perda de calor latente da sudorese depende da diferença de pressão de vapor de água junto à pele e no ar ambiente, da permeabilidade da vestimenta e da humidade na pele. Este processo de dissipação de calor é prejudicado porque o ar entre a pele e o EPI fica saturado.

Devido ao desconforto térmico provocado pela utilização dos EPI agrícolas, é comum se observar que muitos trabalhadores rurais optam por não utilizá-los ou por deixar de utilizar alguns itens dos EPI (Veiga et al., 2007 ; Almeida et al., 2012).

Um EPI agrícola é composto basicamente pelos seguintes itens : bota de borracha ; calça (75\% impermeável ; $25 \%$ permeável) ; camisa de algodão ; camisa de manga longa ; avental impermeável; boné de tecido com protetores para o pescoço e viseira de material plástico transparente ; e luvas impermeáveis. Na Figura 1 é possível observar o EPI agrícola que foi objeto desse estudo. Apesar de existirem diversos fabricantes, não há diferença significativa entre os modelos de EPI agrícolas comercializados.

Figura 1. Lavrador se preparando para iniciar o trabalho de pulverização de agrotóxico.

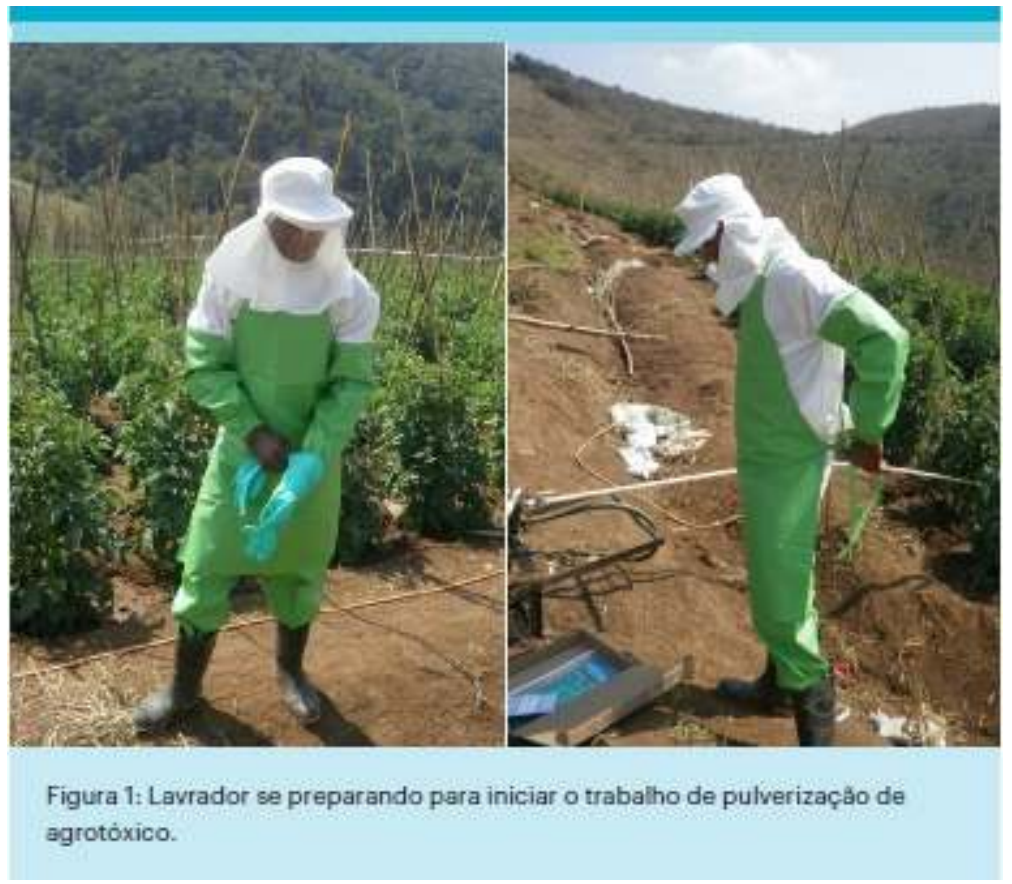




\section{3 - Material e Métodos} processo de pulverização de agrotóxicos. Para isso, em cada etapa do processo de trabalho foi necessário monitorar o esforço realizado através da frequência cardíaca, o (des)conforto térmico promovido pela vestimenta através da Temperatura Corporal (TCC) e a sensação de conforto térmico através de uma avaliação subjetiva.

Apesar de variar de pessoa para pessoa, a sensação de conforto térmico é influenciada por fatores, tais como : composição corporal, idade, forma física. Desta forma, este estudo fez uma avaliação por questionário dessa sensação térmica e comparou os resultados com os dados da temperatura corporal durante uma atividade monitorada.

\section{1 - Descrição do Processo de Trabalho}

Uma etapa importante deste estudo foi observar e descrever globalmente o processo de trabalho na lavoura de tomate. Não foi realizado acompanhamentos e análises detalhadas da atividade de trabalho. No entanto, esta etapa preliminar permitiu descobrir as etapas mais críticas do processo de trabalho sobre o aspecto da utilização de EPI, esforço físico e exposição térmica.

\section{2 - Avaliação do Esforço Físico dos Trabalhadores}

24 A frequência cardíaca se altera com pequenas mudanças na intensidade das atividades laborais. O monitoramento desta variável possibilita estimar a intensidade da atividade laboral e dos pontos de maior esforço dos trabalhadores, além de identificar os pontos onde houve variação no esforço.

o esforço físico realizado pelos trabalhadores rurais foi estimado através do monitoramento da frequência cardíaca no processo de trabalho das atividades estudadas. Após a etapa prévia de observação participante que perdurou um período completo de uma lavoura (120 dias), selecionou-se como objeto deste estudo as etapas das atividades laborais de maior exigência física do lavrador, de maior risco de contaminação por aplicação de agrotóxicos e de maior potencial de exposição térmica.

Por isso, cada um dos dois trabalhadores rurais selecionados para este estudo utilizou um monitor de frequência cardíaca digital capaz de registrar a cada segundo a média da frequência cardíaca dos últimos cinco segundos. 0 monitor de frequência cardíaca utilizado tem o formato de um relógio de pulso comum e recebe informações através de um sistema sem fio de um sensor em formato de fita elástica posicionado entorno do tórax do indivíduo. No monitor foi possível acompanhar o comportamento da frequência cardíaca, registrando esses valores para posterior análise. Ressalta-se que não foi objetivo deste estudo tentar fazer uma correlação da frequência cardíaca dos trabalhadores com as variáveis temperatura timpânica e sensação térmica. Da mesma forma, não foi possível relacionar os dados de frequência cardíaca com os modos operatórios de cada operador. 0 monitor de frequência cardíaca não foi sincronizado com imagens das atividades de trabalho. 


\section{3 - Os trabalhadores acompanhados}

27 Conforme mencionado, neste estudo foram selecionados dois trabalhadores rurais voluntários, que passam a ser identificados como "A" e "B". Estes trabalhadores vestindo os EPI agrícolas completos foram monitorados nas suas atividades de pulverização de agrotóxicos em três momentos escolhidos do processo de trabalho da lavoura do tomate.

28 Os dois trabalhadores rurais tinham 39 e 45 anos de idade e 21 e 26 anos de trabalho na lavoura, respectivamente. Os dados antropométricos do trabalhador A foram : Altura de $1,77 \mathrm{~m}$; Massa Corporal de 74,3 kg; IMC de 23,7; e percentual de gordura de $9 \%$. Os dados antropométricos do trabalhador B foram : Altura de 1,74m ; Massa Corporal de $71,1 \mathrm{~kg}$; IMC de 23,5 ; e percentual de gordura de $12 \%$. Pode-se notar que as avaliações antropométricas desses trabalhadores foram muito semelhantes, não apresentando nenhuma diferença significativa.

\section{4 - Descrição do Experimento}

Um ciclo completo de uma lavoura de tomate foi monitorado. A coleta de dados primários desta pesquisa ocorreu em três momentos (três dias distintos) selecionados do processo de trabalho. 0 primeiro monitoramento ocorreu no início da $3^{\mathrm{a}}$ fase de desenvolvimento da lavoura (30/35 dias a 70/75dias); o segundo monitoramento ocorreu no final da $3^{\mathrm{a}}$ fase de desenvolvimento da planta ; e o terceiro monitoramento ocorreu no início da $4^{a}$ fase de desenvolvimento da planta (produtiva). o período exato de ocorrência de cada um desses monitoramentos com coleta de dados primários foi :

30 a) primeiro monitoramento ocorreu durante o processo de aplicação de agrotóxicos quando as plantas tinham 12 dias no solo e cerca de $10 \mathrm{~cm}$ de altura.

31 b) segundo monitoramento ocorreu durante o processo de aplicação de agrotóxicos quando as plantas tinham 48 dias no solo e cerca de $90 \mathrm{~cm}$ de altura.

32 c) terceiro monitoramento ocorreu durante o processo de aplicação de agrotóxicos quando as plantas tinham 75 dias no solo e cerca de 1,80 m de altura.

33 A Figura 2 representa o local onde foi realizado o estudo. A área destacada em vermelho corresponde à porção da lavoura onde o trabalhador rural A foi responsável. A área destacada em azul corresponde à porção da lavoura onde o trabalhador rural B foi responsável. Cada uma das áreas destacadas continha aproximadamente 3.500 pés de tomate. 
Figura 2. Lavoura de tomate onde foi realizada a coleta de dados do estudo. Em vermelho a área sob cuidado do trabalhador rural A e em azul a área sob cuidado do trabalhador rural B.

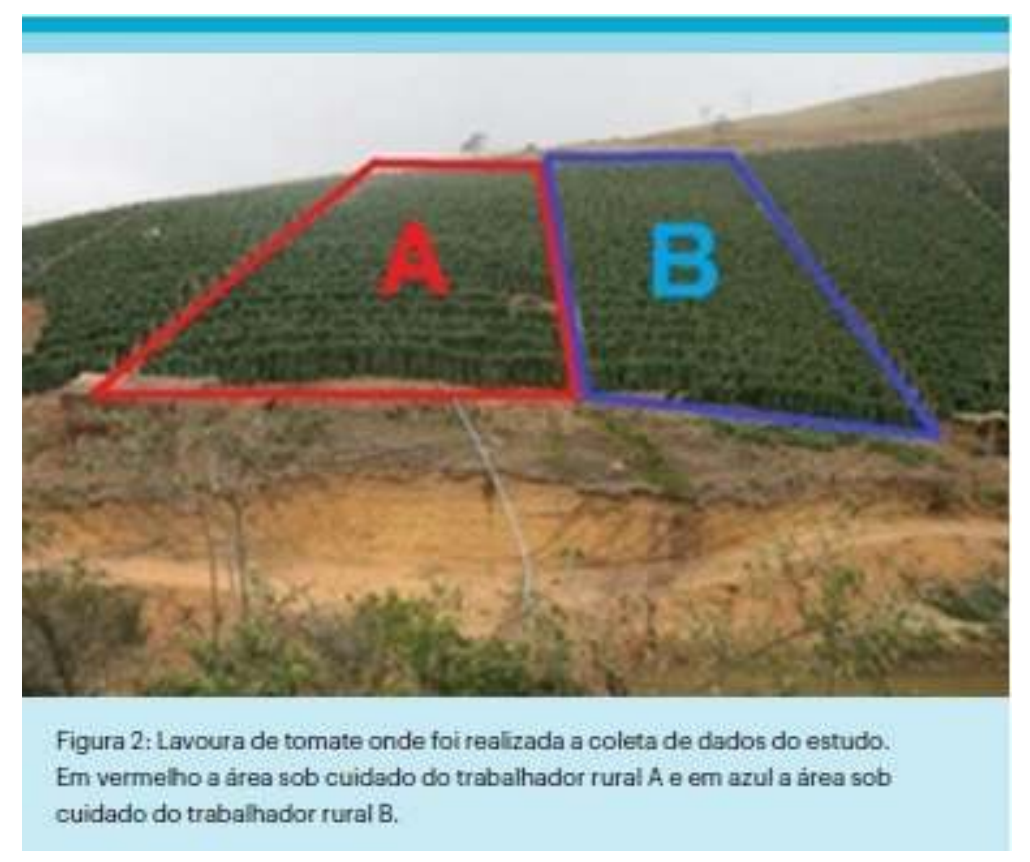

\section{5 - Avaliação da Temperatura Corporal}

Este estudo avaliou a temperatura corporal durante o processo de trabalho através da medida timpânica, seguindo intervalos de 10 minutos cada, com um termômetro digital nos dois trabalhadores selecionados para o estudo. Em estudo anterior, Almeida \& Veiga (2010) descreveram com detalhes as vantagens e as desvantagens de cada método de medição da temperatura corporal, destacando que a temperatura timpânica possui baixo custo e elevada confiabilidade.

Para avaliar a confiabilidade do método da temperatura timpânica através do termômetro digital utilizado, foi realizado um pré-teste de avaliação da temperatura corporal em 12 voluntários do sexo masculino, saudáveis, não sedentários, fisicamente ativos. Para cada um dos 12 voluntários foram repetidas 10 vezes as medidas das temperaturas timpânicas. Entre uma medida e outra, houve um intervalo de 30 segundos para diminuir o risco de interferência entre as medidas, que foram sempre tomadas no ouvido direito.

\section{6 - Avaliação Subjetiva do Conforto Térmico}

Uma avaliação subjetiva do conforto térmico foi feita através do questionário proposto na ISO 10551/95. Este estudo utilizou-se de três perguntas para avaliar o conforto térmico dos dois trabalhadores rurais. Essas perguntas foram repetidas durante cada fase do processo de monitoramento. Seguindo a escala Likert, para cada resposta foi atribuído um valor, com a finalidade de permitir avaliar a correlação entre os valores subjetivos de conforto térmico e os valores objetivos de temperatura timpânica.

Para conseguir resultados mais confiáveis, cada vez que foi tomada uma medida de temperatura timpânica de um dos trabalhadores rurais selecionados, em intervalos de 
10 minutos cada, este estudo coletou, simultaneamente, as respostas para cada uma das três perguntas do questionário.

As três perguntas e as possibilidades de repostas para cada pergunta com a valoração entre parênteses das respostas possíveis estão indicadas a seguir.

a) 1 Pergunta: “COM RELAÇÃO A SUA SENSAÇÃO TÉRMICA, COMO VOCÊ ESTÁ SE SENTINDO NESSE MOMENTO ?" - Respostas Possíveis : com muito calor (3) ; com calor (2) ; levemente com calor (1); neutro (0) ; levemente com frio (-1); com frio (-2) ; com muito frio (-3).

b) $2^{\text {a }}$ Pergunta : "DE QUE MANEIRA VOCÊ SE ENCONTRA NESSE MOMENTO ?"Respostas Possíveis : confortável (0) ; levemente inconfortável (1) ; inconfortável (2); muito inconfortável (3).

41 c) 3" Pergunta : "COMO VOCÊ PREFERIA ESTAR SE SENTINDO AGORA ?"- Respostas Possíveis : Bem mais aquecido (-3); mais aquecido (-2) ; um pouco mais aquecido (-1) ; assim mesmo (0); um pouco mais refrescado (1); mais refrescado (2); bem mais refrescado (3).

\section{4 - Resultados}

42 No pré-teste realizado para aferir a confiabilidade do método da temperatura timpânica foram realizadas medidas de temperatura em 12 voluntários, cada uma repetiu a aferição 10 vezes para avaliar a precisão do método. Neste pré-teste foram tomadas medidas da temperatura timpânica de indivíduos em repouso. 0 grupo foi composto de 12 voluntários do sexo masculino com idade média de 22,1 anos, máxima de 24 anos, mínima de 21 anos e desvio padrão de 1,15.

Observou-se que os valores obtidos das temperaturas timpânicas apresentaram uma dispersão pequena em torno da média (baixo desvio padrão), indicando que os valores obtidos foram significativos para representar a medida real da temperatura corporal. Os resultados médios das temperaturas timpânicas também apresentaram pouca variabilidade com relação à média das temperaturas que foi $36,78{ }^{\circ} \mathrm{C}$ (variando de 36,61 a $36,98^{\circ} \mathrm{C}$ ) e a média dos desvios-padrões que foi $0,15^{\circ} \mathrm{C}$ (variando de 0,07 a $0,21^{\circ} \mathrm{C}$ ).

As etapas do processo de trabalho na cultura do tomate foram identificadas através de observação de um ciclo completo de lavoura. 0 ciclo completo de uma lavoura vai desde o plantio até a colheita do tomate e tem duração média estimada de 120 dias. Este período varia com diversos fatores, e.g. irrigação, pragas, solo, medidas defensivas e principalmente o clima. Cada trabalhador cuida de 3.500 plantas (aproximadamente) numa plantação estaqueada em terreno com elevada inclinação, conforme descrito a seguir.

$451^{a}$ etapa : Preparo do solo - Nesta primeira etapa não há aplicação de agrotóxicos e corresponde ao preparo do solo para receber as mudas de tomate (transplante) através da aradagem, do enriquecimento e da covação. Nesta primeira etapa, não há utilização de EPI. Esta é a fase de maior esforço físico para os trabalhadores. Inicialmente, é feito um preparo do solo mecânico (tratores), seguido de uma intensa atividade manual.

$2^{a}$ etapa : Plantio - Na segunda etapa também não há aplicação de agrotóxicos e consiste no plantio das sementes em bandejas específicas e na manutenção do seu desenvolvimento em estufa. Após este período o tomateiro é transplantado da bandeja 
para a cova (solo). Nesta segunda etapa, não há utilização de EPI. Este é o período de menor esforço físico para os trabalhadores.

$3^{\mathrm{a}}$ etapa : do $30^{\circ}$ ao $75^{\circ}$ dia - Nesta terceira etapa, há utilização de agrotóxicos e, portanto, necessidade de utilização de EPI. Esta etapa se inicia após o transplante da planta para o solo e vai até as plantas atingirem um metro de altura. Nesta etapa, os ciclos de aplicação de agrotóxicos são mais rápidos, pois as plantas ainda estão com um porte pequeno, necessitando de menor quantidade de agrotóxicos. Contudo, há uma exigência física progressiva conforme o crescimento das plantas. No início da etapa, o trabalhador leva cerca de 40 minutos para aplicar agrotóxicos nas 3.500 plantas. No final da etapa, após as plantas estarem com cerca de um metro, o tempo de aplicação dobra, chegando a 80 minutos por ciclo de aplicação.

$4^{\mathrm{a}}$ etapa : Fase produtiva - Nesta quarta etapa há utilização intensa de agrotóxicos e necessidade de EPI. Esta etapa ocorre entre o $75^{\circ}$ e o $100^{\circ}$ dia, quando a planta se desenvolve de 1 a 1,8 metros, indo até o fim da fase produtiva do tomate. Esta é a etapa produtiva do tomateiro propriamente dita. A etapa pode durar entre 20 e 40 dias, dependendo do clima. Um clima mais quente acelera a lavoura. A aplicação de agrotóxicos é intensa durante toda a etapa. Há uma grande exigência física dos trabalhadores porque as plantas já atingiram sua fase completa de desenvolvimento, demandando maior tempo de aplicação de agrotóxicos em cada ciclo. A exposição do trabalhador ao agrotóxico é maior nesta etapa.

A Tabela 1 consolida uma estimativa do esforço físico e da exposição térmica para cada uma das fases do processo de trabalho.

\begin{tabular}{|c|c|c|c|}
\hline FASE & PERIODO & $\begin{array}{l}\text { ESFORÇO } \\
\text { FISICO }\end{array}$ & $\begin{array}{l}\text { EXPOSICCAO } \\
\text { TERMICA }\end{array}$ \\
\hline $1^{2}$-PREPARO DO SOLO & Antes do plantio & Muito alto & Aita \\
\hline $2^{\mathrm{a}}$ - PLANTIO NA BANDEJA & 0 a $30^{\circ}$ dia & Baixo & Baixa \\
\hline $\begin{array}{l}3^{a} \text {-TRANSPLANTE ATE } \\
\text { ATINGIR } 1 \mathrm{M}\end{array}$ & $30^{\circ}$ a $75^{\circ}$ dia & Médio & Alta \\
\hline $\begin{array}{l}4^{n} \text { - DE 1M ATE INICIO } \\
\text { DA PRODUÇAO (1,8M) }\end{array}$ & $75^{\circ}$ a $100^{\circ} \mathrm{dia}$ & Aito & Muito Alta \\
\hline $\begin{array}{l}5^{2}-\text { COLETA DO TOMATE } \\
\text { FINAL DA PRODUÇAO }\end{array}$ & $100^{\circ}$ a $120^{\circ}$ dia & Alto & Muito Alta \\
\hline $\begin{array}{l}\text { Tabela 1: Tabela de esforç } \\
\text { lavoura de tomate. }\end{array}$ & e exposiçäot & a em dife & fases da \\
\hline
\end{tabular}

TABELA 1 : Tabela de esforço físico e exposição térmica em diferentes fases da lavoura de tomate

A atividade de pulverização de agrotóxicos exige elevado esforço físico que leva os trabalhadores rurais a se hidratar. Muito embora sempre houvesse água disponível para consumo, observou-se que os trabalhadores não se hidratavam adequadamente. 
Esta situação foi mais crítica nas etapas finais, que exigiam ciclos mais longos de aplicação de agrotóxicos. A justificativa apresentada foi que uma maior qualidade de reposição hídrica, reduziria a produtividade, pois exigiria um grande número de intervalos.

Um ponto crítico do processo de trabalho foi na atividade de covação, onde o lavrador emprega muita força física, durante longos períodos, com exposição ao sol e com grande demanda energética. Nesta etapa, não há risco de contaminação por agrotóxicos. Contudo, é uma atividade laboral intensa com exposição ao calor, ocasionando grande acúmulo de carga térmica. Muito embora a prática seja não utilizar EPI pela ausência de agrotóxicos, equipamentos de proteção deveriam ser utilizados para minimizar a exposição térmica.

51 Outro ponto crítico observado foi no período em que as plantas já atingiam uma altura maior (1 metro) até o fim da fase produtiva. A partir desse ponto a demanda por agrotóxicos é maior devido à suscetibilidade do tomateiro a pragas, especialmente em ambientes quentes e úmidos. Em plantas maiores, o tempo gasto para pulverizar agrotóxicos é mais elevado, demandando um esforço físico e uma exposição térmica bem maior.

52 Neste estudo foram escolhidas as três etapas para serem monitoradas. Estas etapas correspondem as atividades laborais onde os trabalhadores necessitam utilizarem EPI devido a pulverização de agrotóxicos. Os registros do monitoramento do esforço físico dos trabalhadores rurais no desenvolvimento dessas atividades encontram-se descritas a seguir. A estimativa do esforço físico dos trabalhadores rurais foi obtida através do monitoramento da frequência cardíaca.

53 O primeiro dia de monitoramento dos trabalhadores rurais - As plantas tinham apenas 12 dias no solo e cerca de $10 \mathrm{~cm}$ de altura. A aplicação de agrotóxicos teve duração de 38min20s na área vermelha (A) e 40min15s na área azul (B). A temperatura ambiente era de $26^{\circ} \mathrm{C}$.

54 O segundo dia de monitoramento dos trabalhadores rurais - As plantas tinham 48 dias no solo e cerca de $90 \mathrm{~cm}$ de altura. A aplicação de agrotóxicos teve duração de 1 h08min45s na área vermelha (A) e 1h04min00s na área azul (B). A temperatura do ar atingiu $29^{\circ} \mathrm{C}$.

O terceiro dia de monitoramento dos trabalhadores rurais - As plantas tinham 75 dias no solo e cerca de $1 \mathrm{~m} 80 \mathrm{~cm}$ de altura. A aplicação de agrotóxicos teve duração de 1h10min15s na área vermelha (A) e 1h04min00s na área azul (B). A temperatura do ar atingiu $26^{\circ} \mathrm{C}$.

As diferenças nas frequências cardíacas entre os trabalhadores foram significativas e são apresentadas com mais detalhes nos gráficos das Figuras 3 e 4. Por exemplo, no primeiro dia observou-se que a frequência cardíaca do trabalhador A teve média de $98 \mathrm{bpm}$, atingindo valores altos (até $143 \mathrm{bpm}$ ) ao final da atividade realizada, o que sugere um esgotamento físico. $\mathrm{O}$ mesmo não ocorre com o trabalhador $\mathrm{B}$, que apresenta uma frequência cardíaca menor, média de $90 \mathrm{bpm}$ e um comportamento regular ao longo de sua jornada de trabalho. As diferenças persistem nos três dias. A abordagem metodológica adotada não nos permite explicar essas diferenças, sugerindo a necessidade de se recorrer a outras mediações como a atividade de trabalho e os modos operatórios para compreende-las. Esse ponto será retomado posteriormente. 
Figura 3. Frequência Cardíaca do trabalhador A no primeiro dia de monitoramento

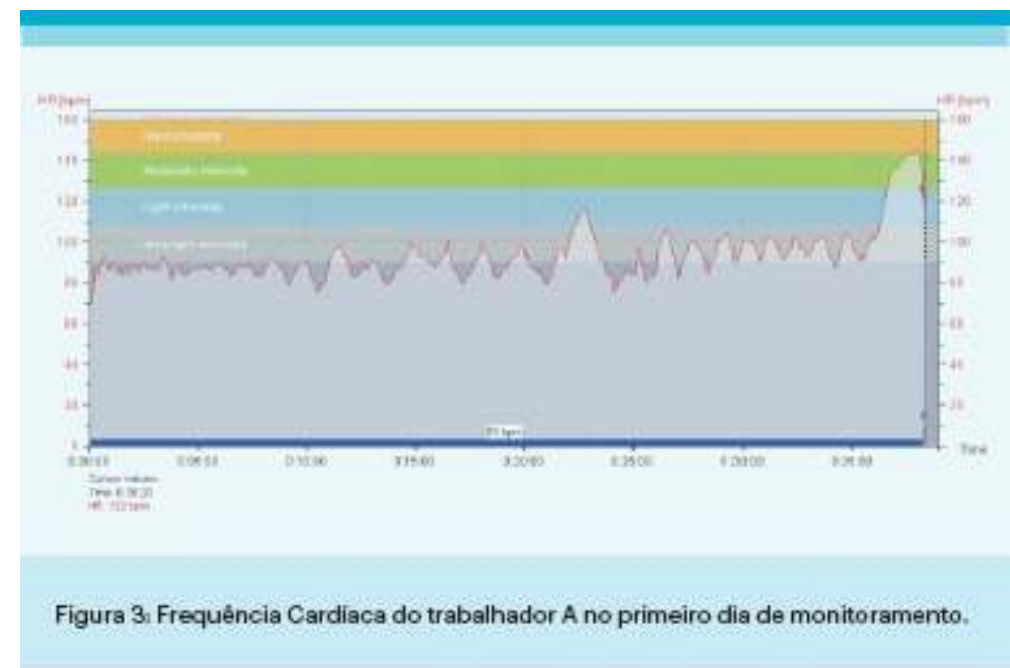

Figura 4. Frequência Cardíaca do trabalhador B no primeiro dia de monitoramento

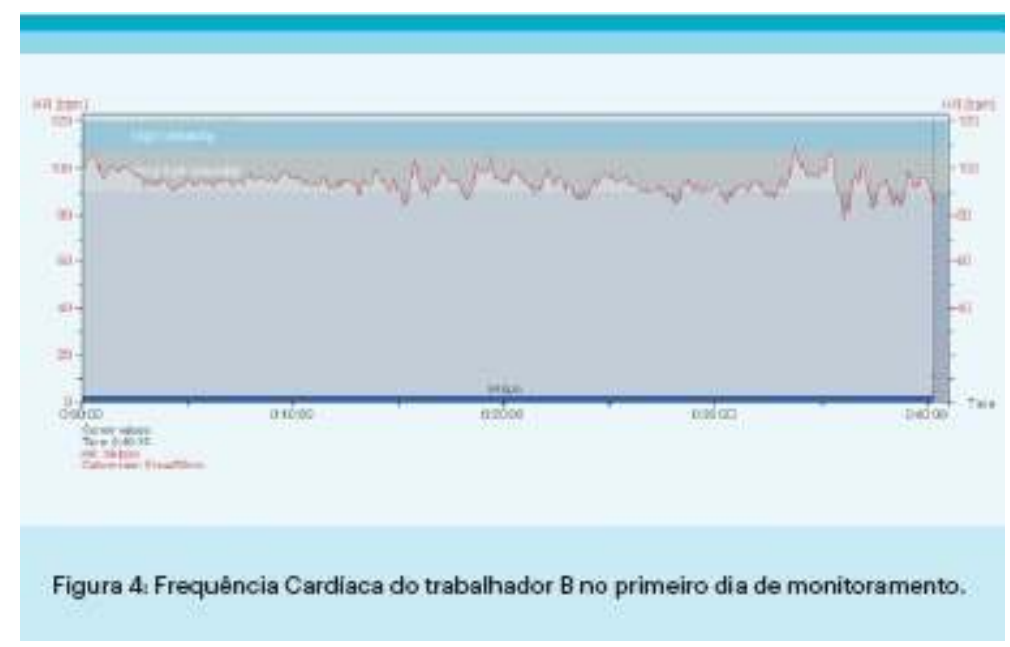

$\mathrm{Na}$ análise da sensação térmica, conforme já mencionado, foi utilizado o questionário proposto pela ISO 10551/95. Seguindo a escala Likert foram atribuídos valores para cada uma das respostas possíveis, para permitir o teste de correlação com os valores obtidos pela aferição da medida timpânica da temperatura. Ao mesmo tempo em que os lavradores respondiam as perguntas do questionário, foi aferida a temperatura timpânica. Os resultados destas avaliações para trabalhadores rurais A e B estão 


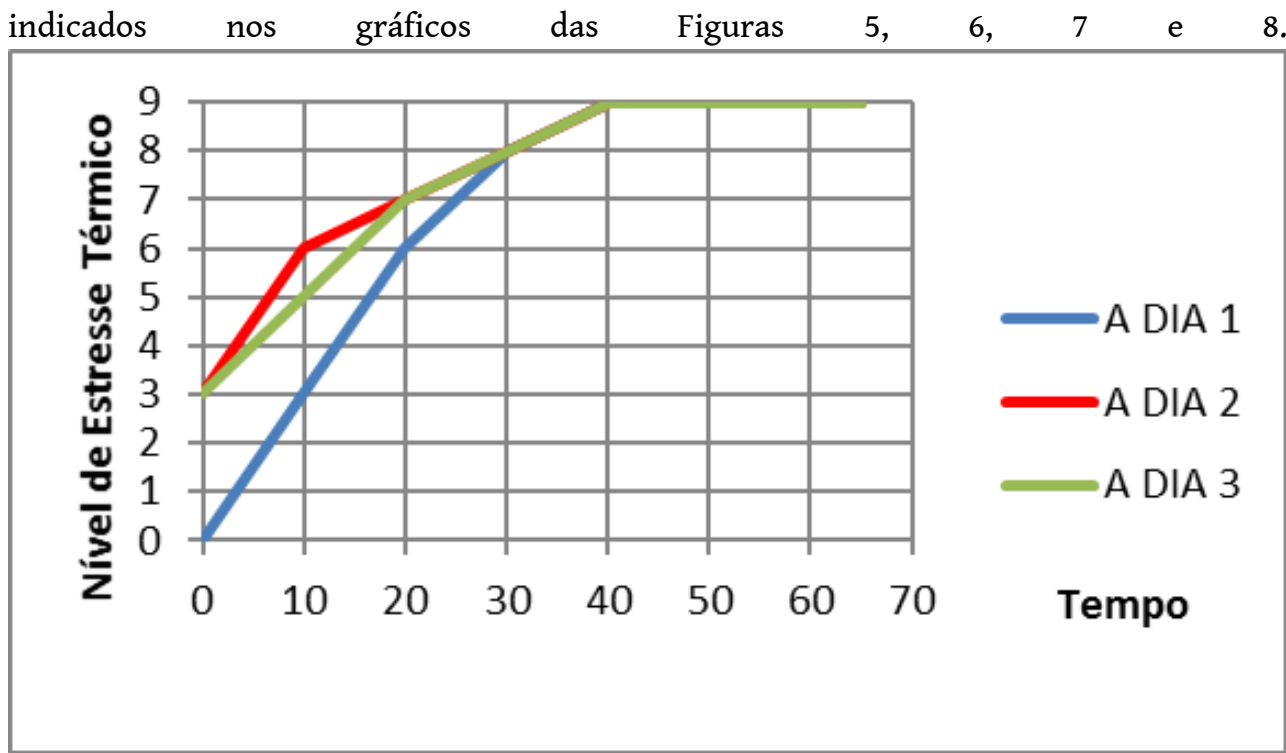

Figura 5. Avaliação da sensação térmica pelo trabalhador $A$

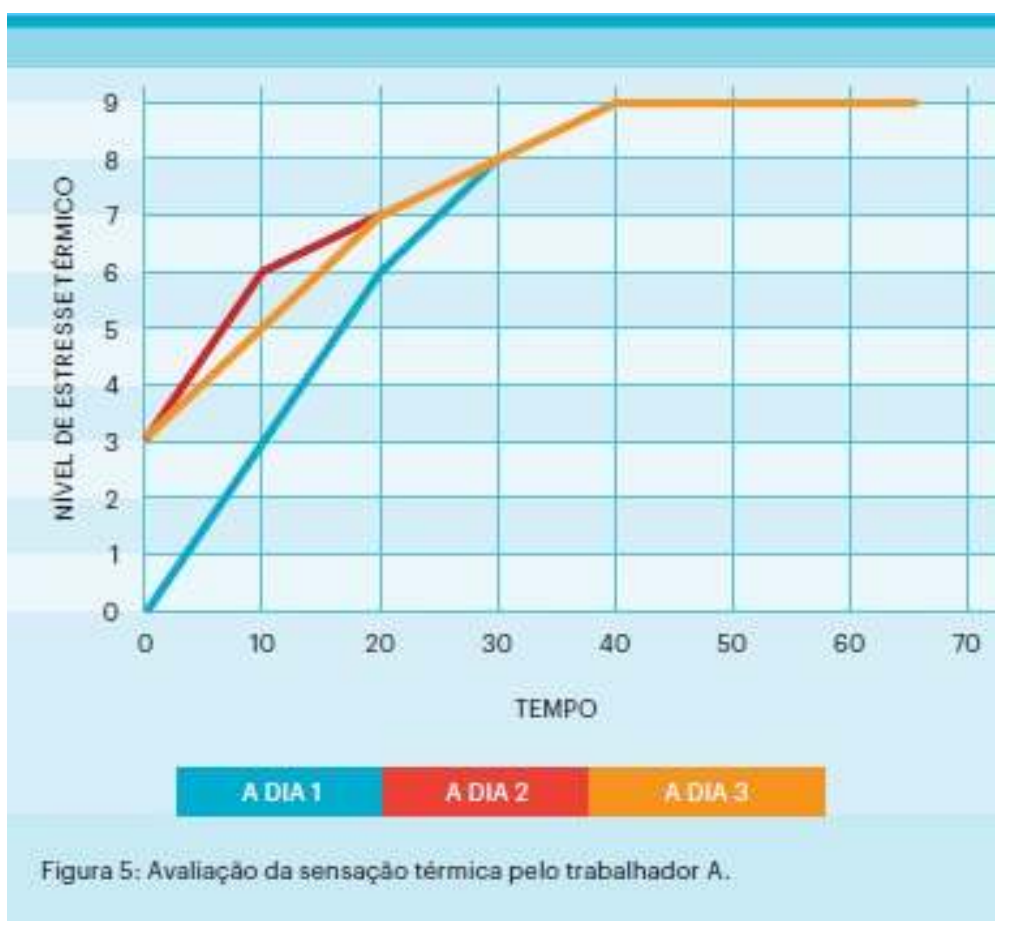


Figura 6. Avaliação da sensação térmica pelo trabalhador B

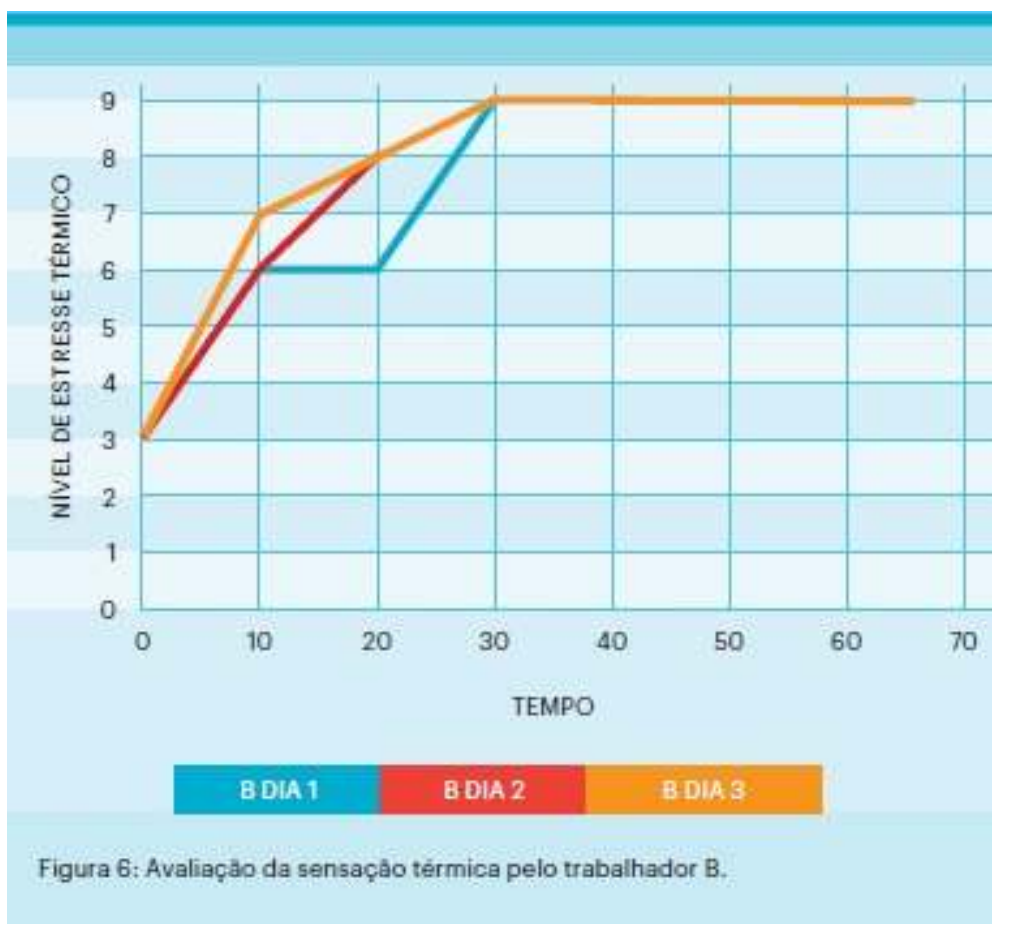

57 Assumindo-se como neutro (pleno conforto térmico) o valor zero em relação à sensação térmica e um valor de 4,5 como de desconforto térmico, pode-se observar que os trabalhadores A e B atingiram o nível de desconforto térmico em menos de 20 minutos. Considerando-se o nível de estresse térmico como valores acima de 7,0, os dois trabalhadores em pouco mais de 20 minutos já estariam realizando atividade com muito desconforto térmico, podendo atingir o estresse térmico.

Ressalta-se que nos casos do segundo e terceiro monitoramento, que corresponderam a pulverizações de agrotóxicos de duração mais longas, os trabalhadores foram expostos a uma carga térmica excessiva e realizaram a atividade por mais de 40 minutos com muito desconforto térmico.

Nos gráficos das Figuras 7 e 8 que apresentam a temperatura timpânica, foi acrescentado os valores estimados pela literatura de elevação de temperatura corporal para um trabalhador executando atividade moderada com roupa leve, ou seja, uma elevação de temperatura linear até atingir $1^{\circ} \mathrm{C}$ em 40 minutos. 
Figura 7. Avaliação da temperatura timpânica do trabalhador A

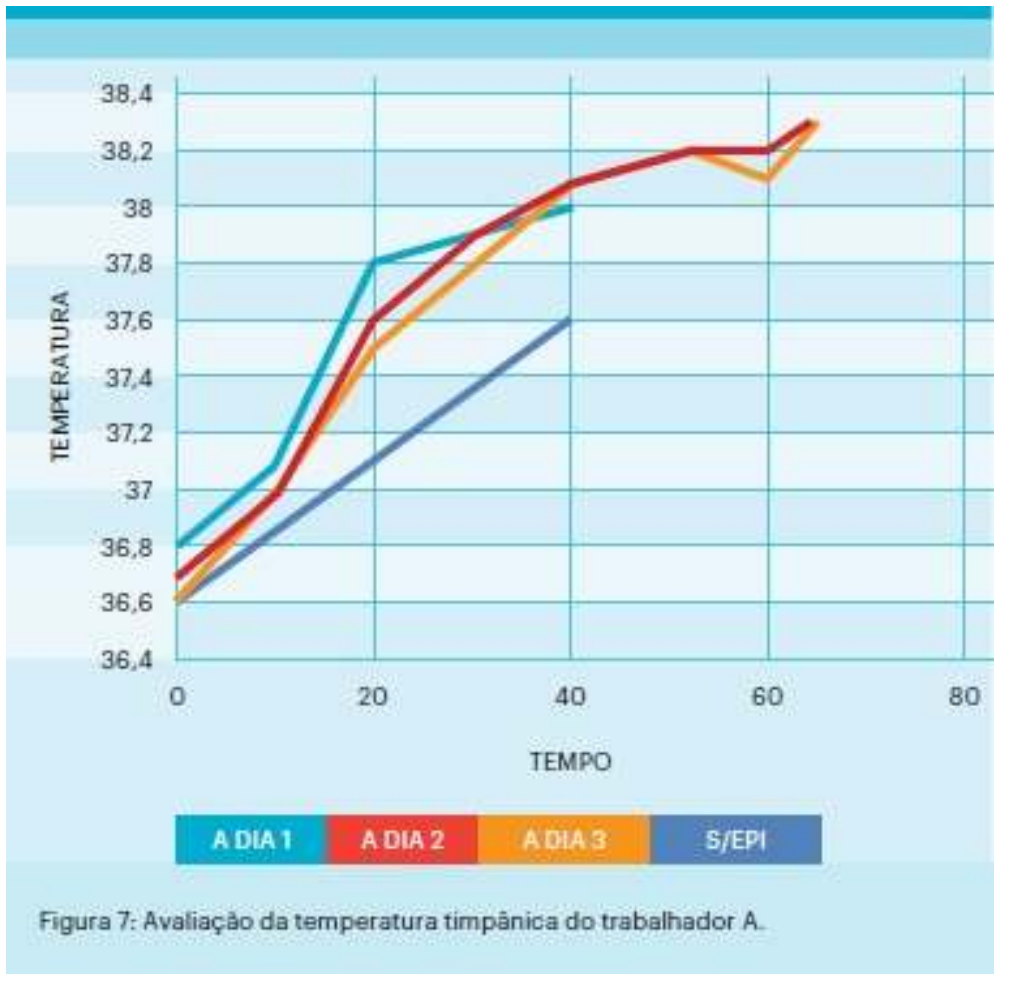

Figura 8. Avaliação da temperatura timpânica do trabalhador B

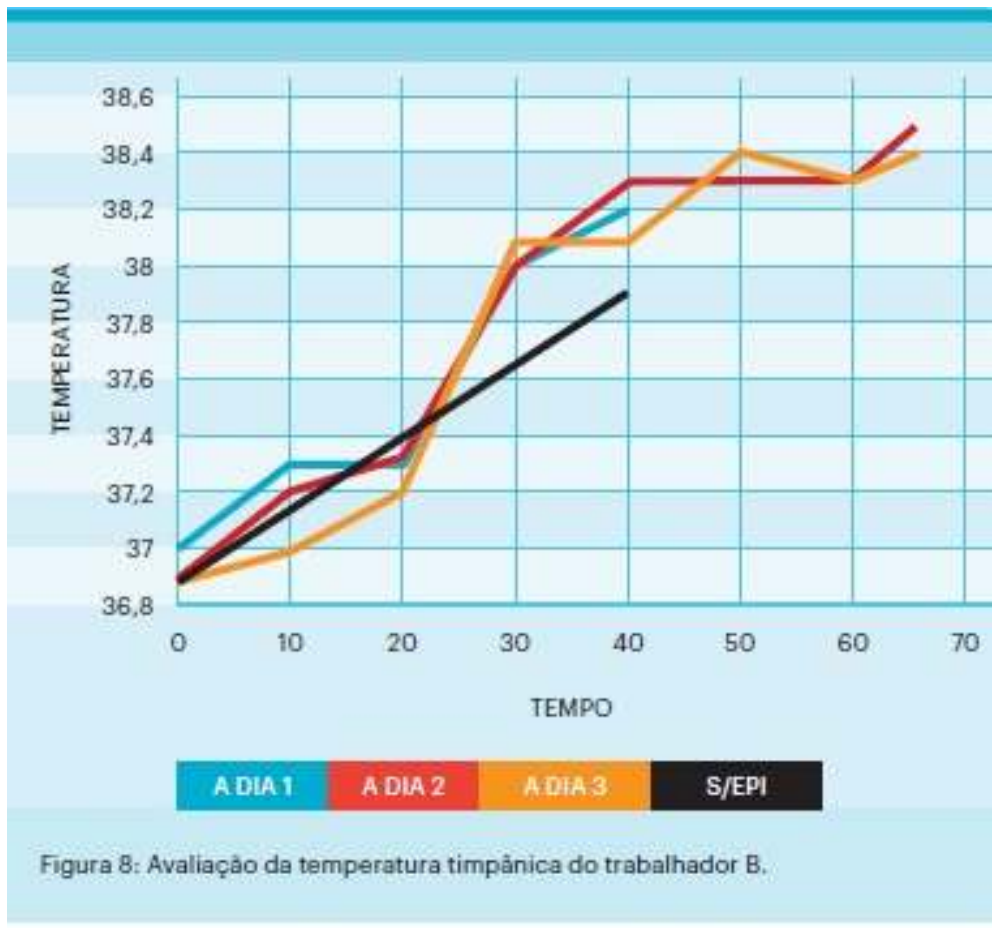

Ressalta-se que qualquer registro de temperatura corporal acima de $37,5{ }^{\circ} \mathrm{C}$ pode ser um indicativo de desconforto térmico. Temperaturas acima de $38{ }^{\circ} \mathrm{C}$ podem ser consideradas como muito desfavoráveis e com risco de estresse térmico. Este pressuposto é corroborado pelos resultados encontrados, destacando-se que toda vez 
que a temperatura corporal atingiu $38^{\circ} \mathrm{C}$, a soma das avaliações de sensação térmica atingiu o valor máximo da escala (nove).

61 Nos gráficos 3 e 4 é possível observar que, os dois trabalhadores atingiram $37,5{ }^{\circ} \mathrm{C}$ por volta de 20 minutos de atividade. Observa-se ainda que os valores da temperatura corporal medido nos trabalhadores rurais que usavam EPI são superiores aos valores encontrados na literatura para elevação da temperatura corporal sem EPI.

Pode-se perceber que os valores encontrados de temperatura corporal nos dois trabalhadores corresponderam às sensações térmicas relatadas. Isto significa que a dificuldade de termorregulação provocada pelo uso dos EPI foi significativa na sensação de desconforto térmico. Todos os resultados apresentados encontram-se sintetizados na Tabela 2.

Tabela 2 : Resultados de Temperatura Timpânica e Avaliação de Sensação Térmica

\begin{tabular}{|c|c|c|c|c|c|c|c|c|c|c|c|c|}
\hline \multirow{4}{*}{$\begin{array}{c}\text { ETAPA } \\
\text { Planta } \\
\text { Durapáo } \\
\text { FC } \\
\text { MEDIA }\end{array}$} & \multicolumn{4}{|c|}{10 Monitaramento } & \multicolumn{4}{|c|}{20 Monitoramento } & \multicolumn{4}{|c|}{$3^{\circ}$ Monitoramento } \\
\hline & \multicolumn{4}{|c|}{$0,10 \mathrm{~m}$ de alturs } & \multicolumn{4}{|c|}{$0,90 \mathrm{~m}$ de althura } & \multicolumn{4}{|c|}{$1,80 \mathrm{~m}$ de altura } \\
\hline & \multicolumn{4}{|c|}{40 minutou } & \multicolumn{4}{|c|}{65 minuton } & \multicolumn{4}{|c|}{70 minutoa } \\
\hline & $98 \mathrm{t}$ & $\mathrm{pm}$ & $90 \mathrm{t}$ & $\mathrm{pm}$ & $92 \mathrm{t}$ & $\mathrm{pm}$ & $115 \mathrm{t}$ & $\mathrm{pm}$ & $87 \mathrm{~b}$ & pm & $129 t$ & $2 \mathrm{pm}$ \\
\hline $\mathrm{Tmin} / \mathrm{Te}$ & $A(T)$ & $A(S)$ & $B(T)$ & $B(\$)$ & $A(T)$ & $A(\$)$ & $B(T)$ & $B(S)$ & $A(T)$ & $A(S)$ & $B(T)$ & $B(S)$ \\
\hline 0 & 36,8 & 0 & 37,0 & 3 & 36,7 & 3 & 36,9 & 3 & 36,6 & 3 & 36,9 & 3 \\
\hline 10 & 37,1 & 3 & 37,3 & 6 & 37,0 & 6 & 37,2 & 6 & 37,0 & 5 & 37,0 & 7 \\
\hline 20 & 37,8 & 6 & 37,3 & 6 & 37,6 & 7 & 37,3 & 7 & 37,5 & 7 & 37,2 & 8 \\
\hline 30 & 37,8 & 8 & 38,0 & 9 & 37,9 & B & 38,0 & 8 & 37,8 & 8 & 38,1 & 9 \\
\hline 40 & 38,0 & 8 & 38,2 & 9 & 38,1 & 9 & 38,3 & 9 & 38,1 & 9 & 38,1 & 9 \\
\hline 50 & & & & & 38,2 & 9 & 38,3 & 9 & 38,2 & 9 & 38,4 & 9 \\
\hline 60 & & & & & 38,2 & 9 & 38,3 & 9 & 36,1 & 9 & 38,3 & 9 \\
\hline
\end{tabular}

Tabela 2. Resultados de Temperatura Timpânica e Avaliaçào de Sensaçào Térmica.

63 Na Tabela 2 pode-se observar a correlação dos valores de temperatura timpânica e sensação térmica. Note-se que não é possível com as informações presentes nesse estudo analisar as variações na frequência cardíaca. Uma análise da frequência cardíaca requer maior detalhamento do processo de trabalho e dos modos operatórios utilizados. Além disso, os três monitoramentos foram executados com grande variação temporal entre eles, dificultado qualquer comparação entre os trabalhadores ou do mesmo trabalhador em monitoramentos diferentes.

As três atividades monitoradas são basicamente semelhantes em intensidade, mas se diferenciam na sua duração. Por isso, pode-se inferir que um trabalhador mais descansado ou em melhor estado físico poderia retardar a elevação de temperatura e reduzir a variação de frequência cardíaca. Esse efeito foi observado no trabalhador A durante o $1^{\circ}$ monitoramento. Percebeu-se que houve um esgotamento físico nos últimos três minutos da atividade, demonstrado por uma elevação significativa da frequência cardíaca nesse período. A frequência cardíaca média do trabalhador A foi afetada por 
essa elevação nos últimos três minutos. Percebe-se que a frequência cardíaca e a temperatura corporal natural dos dois trabalhadores são diferentes. Observou-se que a frequência cardíaca do trabalhador B variou do $1^{\circ}$ para os outros dois monitoramentos, o que pode indicar a interferência de alguns fatores externos ou estratégias operatórias diferenciadas.

Os resultados apresentados na Tabela 2 indicam os efeitos negativos da utilização de EPI na variação da temperatura corporal com consequente interferência na sensação térmica dos trabalhadores rurais durante o processo de aplicação de agrotóxicos.

O teste de correlação feito entre as temperaturas timpânicas aferidas no primeiro, segundo e terceiro dia de coleta de dados no campo e os valores atribuídos às respostas possíveis para as perguntas propostas pela ISO 10551/95 apresentaram um taxa de correlação elevada. A correlação entre os resultados dos valores das temperaturas timpânicas e dos valores estimados de sensação térmica do trabalhador A foi de 0,918 e do trabalhador B foi de 0,851 , demostrando uma coerência entre os valores medidos de temperatura corporal e a sensação térmica dos trabalhadores.

Os testes efetuados indicaram um alto grau de correlação entre a temperatura timpânica e a percepção da sensação térmica dos trabalhadores rurais. Esse resultado confirma a possibilidade de utilização da medida timpânica para verificação do nível de conforto térmico durante uma jornada de trabalho com grau significativo de confiabilidade.

O desenvolvimento de EPI mais eficazes depende de novos estudos na área de tecnologia combinados com estudos mais detalhados sobre as atividades desses trabalhadores. A inadequação dos EPI aos processos de trabalho ocorre devido a uma série de fatores. Não basta tentar tornar um processo de trabalho mais seguro, apenas recomendando EPI. O EPI deve ser adequado a atividade e às condições de sua utilização.

Existe carência de métodos que avaliem a resposta fisiológica a exposições térmicas provocadas pelas vestimentas. Os testes de aprovação e as pesquisas sobre EPI costumam avaliar a eficácia dos equipamentos de proteção contra um agente específico. Essas avaliações serão sempre parciais e não garantem a eficiência dos EPI.

Os resultados encontrados mostraram que as vestimentas (EPI) interferem no processo de termorregulação corporal. As informações sobre parâmetros de conforto térmico não estão amplamente disponíveis.

71 A maioria dos EPI utilizados na agricultura não foi projetada para este fim, foram adaptados dos projetos de EPI para serem utilizados na indústria. Há necessidade de se determinar parâmetros específicos de acordo com cada processo de trabalho. Essas variáveis poderiam apoiar o desenvolvimento de EPI mais seguros e eficientes.

\section{5 - Conclusões}

Este estudo analisou o conforto térmico dos EPI utilizados na agricultura para proteger os trabalhadores da contaminação por agrotóxicos. Os resultados encontrados mostraram que os EPI prejudicaram o processo de termorregulação, causando desconforto térmico nos trabalhadores rurais. 

em sua concepção. Pode-se dizer que, em algumas etapas do processo de trabalho, eles até colocam em risco os trabalhadores rurais, ao invés de protege-los. Os EPI ainda são projetados e fabricados dentro de uma visão de proteção apenas contra um único fator, no caso dos EPI agrícolas contra a contaminação por agrotóxicos, o que mesmo nesse caso é questionado por outros estudos (Veiga et al. 2007). Um projeto de EPI que cause desconforto térmico, que não permita a ventilação e a dissipação de calor, resultando num aumento da temperatura corporal não pode ser considerado como um projeto acabado e eficiente. $O$ projeto adequado de EPI ainda é um problema em aberto na literatura.

81 Há necessidade de se desenvolver projetos que utilizem novos materiais e que sejam específicos para cada processo de trabalho, considerando todos os seus potenciais benefícios e riscos à saúde. O projeto dos EPIs necessita integrar esse fatores numa abordagem de projeto que possibilite o desenvolvimento da apropriação sistêmica por 
operadores, empresas e o meio social no qual eles estão inseridos. Trabalhos desenvolvidos por Mendes, Pueyo, Lima, Duarte e Béguin (2012 e 2013) e Mendes (2014) procuram avançar nessa direção e ajudam a compreender o que está em jogo na noção da apropriação sistêmica.

\section{BIBLIOGRAFIA}

Almeida, R.A.C.S., \& Veiga, M.M. (2010). Processo de trabalho rural e EPIS : discussão sobre termorregulação corporal. Revista P\&D em Engenharia de Produção, 08(02), 29-39.

Almeida, R.A.C.S., Veiga, M.M., Duarte, F.J.C.M., Meirelles, L.A., \& Veiga, L.B.E. (2012). Thermal comfort and personal protective equipment (PPE). Work, 41, 4979 - 4982.

Correia, E.L.S. (2005). Modelo Térmico aplicado à caracterização do conforto térmico proporcionado pelo vestuário. Tese de Mestrado. Universidade do Minho, Braga, Portugal.

Farrington, R.B., Rugh, J.P., Bharathan, D., \& Burke, R. (2004). Use of a Thermal Manikin to Evaluate Human Thermoregulatory Responses in Transient, Non-Uniform, Thermal Environments. SAE International. doi: 10.4271/2004-01-2345.

Gavin, T. (2003). Clothing and thermoregulation during exercise. Sports Medicine, 33(13), 941-947.

Guérin F., Laville A., Daniellou F., Duraffourg J., \& Kerguelen, A. (2007). Comprendre le travail pour le transformer : la pratique de l'ergonomie ( $5^{\mathrm{e}}$ edition). Lyon-Montrouge : ANACT.

Guyton, A., \& Hall, J. (2006). Tratado de fisiologia médica (11⿳亠丷 Ed.). Rio de Janeiro : Elsevier.

Havenith, G. (1999). Heat balance when wearing protective clothing. Annals of Occupational Hygiene, 43(5), 289-296. doi: 10.1093/annhyg/43.5.289.

Lim, C.L., Byrne, C., \& Lee, J.K.W. (2008). Human Thermoregulation and Measurement of Body Temperature Exercise and Clinical Settings. An Acad Med Singapore, 37, 347-353.

McArdle, W.D., Katch, F.I., \& Katch, V.L. (2003). Fisiologia do exercício : Energia, nutrição e desempenho humano (5ªd.). Rio de Janeiro : Guanabara Koogan.

Mendes, R.W.B., (2014). Apropriação sistêmica de inovações tecnológicas para a prevenção : o caso do controle de poeira em mineradoras de granite. Tese de Doutorado. Programa de Engenharia de Produção - PEP/COPPE/UFRJ.

Mendes, R.W.B., Pueyo, V., Lima, F.P.A., Duarte, F.J.C.M., \& Béguin, P. (2013). O agir do trabalhador na prevenção de silicosa : a história da umidificação. In A. P. Simonelli \& D. Rodrigues (Eds.), Saúde e trabalho : Velhas questões, novas perspectivas (pp. 393-408). São Paulo : Roca.

Mendes, R.W.B., Pueyo, V., Lima, F.P.A., Duarte, F.J.C.M, \& Béguin, P. (2012). La prévention comme innovation : petite histoire de l'humidification, du macro au micro en passant par le méso. Comunicação apresentada no 47ème Congrès International de la Société d'Ergonomie de Langue.

Moran, D.S., \& Mendal, L. (2002). Core temperature measurement methods and current insights. Sports Medicine, 32(14), 879-885. 
Prek, M. (2004). Thermodynamical analysis of human thermal comfort. Special Issue from The Second ASME-ZSIS International Thermal Science Seminar (ITSS II), Bled, Slovenia.

Ruas, A.C. (2002). Sistematização da avaliação de conforto térmico em ambientes edificados e sua aplicação num software. Tese de doutorado. Universidade Estadual de Campinas, São Paulo, Brasil.

Veiga, M.M., Duarte, F.J.C.M., Meirelles, L.A., Garrigou, A., \& Baldi, I. (2007). A contaminação por agrotóxicos e os equipamentos de proteção individual (EPIs). Revista Brasileira de Saúde Ocupacional, 32(116), 57-68.

Wood, L. (2004). Heat resistant. Occupational Health, 56(7), 25-29.

\section{RESUMOS}

O metabolismo humano produz calor devido ao esforço físico nas atividades laborais. O corpo humano funciona como sistema termodinâmico que mantem a temperatura corporal constante. A utilização de Equipamento de Proteção Individual (EPI) dificulta a dissipação do calor gerado e a manutenção da temperatura corporal num nível confortável. Este estudo analisou a interferência dos EPI no conforto térmico dos trabalhadores rurais através de medições das frequências cardíacas e das temperaturas corporais dos trabalhadores durante a pulverização de agrotóxicos. Também foram feitas avaliações da sensação térmica dos trabalhadores através de um questionário. Os resultados encontrados demonstraram : (i) a inadequação dos EPI agrícolas, devido apresentarem uma interferência negativa no processo de termorregulação corporal e (ii) a existência de diferenças individuais significativas entre os trabalhadores monitorados. Este estudo mostrou, ainda que há uma correlação forte entre a avaliação da sensação térmica dos trabalhadores e da temperatura corporal medida.

El metabolismo humano produce calor en las actividades laborales. El cuerpo humano funciona como un sistema termodinámico que mantiene constante la temperatura corporal. El uso de equipo de protección personal (EPP) dificulta la disipación del calor generado y el mantenimiento de la temperatura corporal a un nivel cómodo. Este estudio analizó la interferencia del EPP agrícola en el confort térmico de los trabajadores. Este estudio realizó mediciones de la frecuencia cardiaca y la temperatura corporal de los trabajadores que utilizan EPP durante el proceso de pulverización de pplaguicidas. Este estudio también hizo evaluaciones subjetivas de la sensación térmica de los trabajadores a través de un cuestionario. Los resultados demostraron : (i) la insuficiencia de proyectos de EPP agrícola, ya que han tenido un impacto negativo en el proceso de termorregulación corporal y (ii) la existencia de importantes diferencias individuales entre los operadores controlados, que pueden estar relacionadas con las estrategias operativas diferentes entre los operadores. Este estudio mostró que hay una fuerte correlación entre la evaluación subjetiva de la sensación térmica y la temperatura corporal.

Métabolisme humain produit de la chaleur dans les activités de travail. Le corps humain fonctionne comme un système thermodynamique. L'utilisation de l'équipement de protection individuelle (EPI) empêche la dissipation de la chaleur générée. Cette étude a analysé l'interférence du EPI agricole dans le confort thermique des travailleurs. Cette étude a effectué des mesures de la fréquence cardiaque et la température corporelle des travailleurs utilisant EPI pendant le processus de pulvérisation de pesticides. Cette étude a également fait des évaluations subjectives de la sensation thermique des travailleurs par le biais d'un questionnaire. Les résultats ont démontré: (i) l'insuffisance des projets d'EPI agricoles parce qu'ils ont eu une interférence négative dans le processus de thermorégulation du corps et (ii) l'existence d'importantes différences individuelles entre les opérateurs contrôlés. Cette étude a montré qu'il 
existe une forte corrélation entre l'évaluation subjective de la sensation thermique et la température corporelle mesurée.

Human metabolism produces heat during labor activities. The human body works as a thermodynamic system maintaining a steady body temperature. The use of Personal Protective Equipment (PPE) jeopardizes the heat dissipation, making difficult to keep ain body temperature at a comfortable level. This study analyzed the interference of PPE in workers' thermal comfort. This study made measurements of heart rate and body temperature of workers using PPE during the process of spraying pesticides. This study also made subjective evaluations of thermal sensation of workers through a questionnaire. The results demonstrated: (i) the inadequacy of PPE projects because they indicated a negative impact on body thermoregulation process and (ii) the existence of significant individual differences between the monitored workers, which may be related to different operating modes. This study showed that there is a strong correlation between the subjective evaluation of the thermal sensation by workers and body temperature measured.

\section{ÍNDICE}

Keywords: personal protective equipment, thermal comfort, pesticide

Palabras claves: equipo de protección personal, confort térmico, plaguicidas

Palavras-chave: équipement de protection individuelle, conforto térmico, agrotóxico

Mots-clés: équipement de protection individuelle, confort thermique, pesticides

\section{AUTORES}

\section{MARCELO MOTTA VEIGA}

Fundação Oswaldo Cruz, Ministério da Saúde - Rua Leopoldo Bulhões, 1480/503 - Rio de Janeiro Brasil - CEP : 22.041-210 ; \& Universidade Federal do Estado do Rio de Janeiro - Rua Voluntários da Pátria, 107 - Rio de Janeiro - Brasil - CEP : 22.20-000. Email : marcelo.veiga@unirio.br

\section{RONALDO ALMEIDA}

Fundação Oswaldo Cruz, Ministério da Saúde - Rua Leopoldo Bulhões, 1480/512 - Rio de Janeiro Brasil - CEP : 22.041-210. Email : ronaldocastelo@yahoo.com.br

\section{FRANCISCO DUARTE}

Instituto Alberto Luiz Coimbra de Pós-Graduação e Pesquisa em Engenharia - (COPPE), Universidade Federal do Rio de Janeiro, Av. Horácio Macedo, 2030, G-209, Prédio do Centro de Tecnologia, Cidade Universitária, Rio de Janeiro Brasil, CEP 21941-914. Email : duarte@pep.ufrj.br 